\title{
(3)
} Revista Prevenção de
Infecção e Saúde

The Official Journal of the Human Exposome and Infectious Diseases Network

\section{Influence of patient's general health status on the outcome of infections}

Influência do estado geral de saúde do paciente sobre o resultado das infecções Influencia del estado de salud general del paciente en el resultado de las infecciones

\begin{abstract}
Débora Cristina Coraça-Huber ${ }^{1}$
${ }^{1}$ Research Laboratory for Biofilms and Implant Associated Infections (BIOFILM LAB), Experimental Orthopedics, University Hospital for Orthopedics and Traumatology, Medical University of Innsbruck, Innsbruck, Austria. Address: Peter-Mayr-Strasse 4b, Room 204, 6020 Innsbruck, Austria. Telephone: +43-512-9003-71697. E-mail: debora.coraca-huber@i-med.ac.at
\end{abstract}

How to cite this article:

Coraça-Huber DC. Influence of patient's general health status on the outcome of infections [Editorial]. Rev Pre Infec e Saúde [Internet]. 2021;7:12685. Available from: https://revistas.ufpi.br/index.php/nupcis/article/view/12685 DOI: https://doi.org/10.26694/repis.v7i0.12685

In the conventional medicine, infections are usually treated as a local disturb, in which only the affected/infected area is taken into consideration. During an infection, the aim of an acute treatment is the reduction or complete elimination of the invading pathogen via administration of an antimicrobial substance, enabling the host immune system to resolve the infection and repair the affected tissue by its own. An interesting fact is which not all individuals react equally to an infecting pathogen. Not all hospitalized patients suffer from nosocomial infections. Not all episodes of influenza are fatal. Even during the SARS-CoV-2 pandemic, it has been observed which the most severe or fatal cases are associated with known pre-existent health conditions. ${ }^{1,2}$ Cases of severe outcomes and deaths among the SARS-CoV-2 infected patients have been also reported in apparently healthy individuals. Although, the question is, if in such cases, the patient did not have an unknown/underlying health condition which weakened the immune system causing the damaging outcomes. ${ }^{3}$

Considering the implant-related infections, some similarities can be observed. Not all implanted patients develop a clinical infection due to the colonization of the implanted devices by microorganisms. The prevalence of dental peri-implantitis, for example, is about $22 \%{ }^{4}$ while the rates for periprosthetic joint infections are between $1-2 \%$ for primary replacements. ${ }^{5}$ This difference can be related to the implant's environment. In contrast to a joint, which is considered sterile, a dental implant gets unavoidably in contact with the oral flora. However, the colonization of an implant surface does not necessarily lead to the occurrence of an infection. In a study carried out in our university hospital, we determined the colonization rate of osteosynthesis implants in patients with no clinical or laboratory signs of infection. We used 
conventional culture, polymerase chain reaction (PCR) of sonication fluid and microscopy. As results, we observed which thirty-two of the examined implants $(56.1 \%)$ showed a positive result either by culture or PCR with coagulase-negative staphylococci being the most commonly identified microorganism (68.1\%). Additionally, scanning electron microscopy imaging demonstrated biofilm-like structures in four of six culture and/or PCR-positive samples. This study was the first to demonstrate bacterial colonization of osteosynthesis implants in healthy patients with no clinical or laboratory signs of infection. Colonization rate was unexpectedly high, and conventional culture was superior to PCR in microbial detection. Although it is known which surface or tissue colonization is a trigger for infection, all the patients involved in this study had the osteosynthesis implants removed without any complications during the course of orthopedic treatment. ${ }^{6}$

The outcomes of a pathogen colonization and development of clinical infection can be strictly related to the general health status of a patient. The World Health Organization (WHO) defined "health" as a state of complete physical, mental and social well-being, and not merely the absence of disease. ${ }^{7}$ Not only the clinical signs of a disease but also the existence of comorbidities as metabolic syndromes, hormonal disbalances and presence of silent chronic inflammations, underlying deficiency of vitamins, minerals and trace elements can influence the body's metabolism and the capacity of the organism to fight pathogens. Also, the quality of life of a patient may influence its susceptibility to infections. It is known which nutrition, stress and physical activity levels also influence the immune system. The influence of stress and negative emotions on the suppression of the immune system and the development of diseases is well explored by the area of psychoneuroimmunology (PNI). In the PNI, stress and emotions are important triggers for biological responses. Both positively and negatively. ${ }^{8,9}$

Research and development of novel antibiotics and antimicrobials, as well as the development of alternatives to the conventional substances, are extremely important. Nanostructured technologies which create anti-biofilm implant surfaces, or the local delivery of antimicrobial substances from implantable devices along with tissue substitutes are also a huge step in the fight against foreign-body infections. Even the measures to contain a pandemic like social distancing, use of facial masks and hygiene are crucial. But, should not we start considering the general health status of a patient more regularly prior to any type of treatment? Global approaches for improving the health status of a patient prior to surgical implantations (those which can be planned in advance) could strengthen the organism and guarantee a more successful healing. Nutritional orientation, stress control, physical activity and weight loss could be examples of such measures. The same can be applied during pandemics as an adjunct, or I would say, one of the main measures to contain the spreading of the disease and avoid health system collapse.

The spread of the awareness about the dangers of underlying health conditions should be the main role of the conventional medicine, as well as the key to successful treatments and control of diseases. 


\section{REFERENCES}

1. Laires PA, Nunes C. Population-based Estimates for High Risk of Severe COVID-19 Disease due to Age and Underlying Health Conditions. Acta Med Port. 2020 Nov [cited 2021 Jun 8]; 33(11):720-725. Available from: http://dx.doi.org/10.20344/amp.14222

2. Walker JL, Grint DJ, Strongman H, Eggo RM, Peppa M, Minassian C, et al. UK prevalence of underlying conditions which increase the risk of severe COVID-19 disease: a point prevalence study using electronic health records. BMC public health. 2021 Mar [cited 2021 Jun 8]; 21:484. Available from: https://doi.org/10.1186/s12889-021-10427-2

3. Irons R. Pandemic ... or syndemic? Re-framing COVID-19 disease burden and 'underlying health conditions'. Soc Anthropol. 2020 May [cited 2021 Jun 8]; 19:10.1111: 1469-8676. Available from: https://doi.org/10.1111/1469-8676.12886

4. Salvi GE, Cosgarea R, Sculean A. Prevalence and Mechanisms of Peri-implant Diseases. J Dent Res. 2017 Jan [cited 2021 Jun 8]; 96(1):31-37. Available from: https://doi.org/10.1177/0022034516667484

5. Li C, Renz N, Trampuz A. Management of Periprosthetic Joint Infection. Hip Pelvis. 2018 Sep [cited 2021 Jun 8]; 30(3):138-146. Available from: https://doi.org/10.5371/hp.2018.30.3.138

6. Knabl L, Kuppelwieser B, Mayr A, Posch W, Lackner M, Coraça-Huber D, et al. High percentage of microbial colonization of osteosynthesis material in clinically unremarkable patients. Microbiologyopen. 2019 Mar [cited 2021 Jun 8]; 8:e00658. Available from: https://doi.org/10.1002/mbo3.658

7. World Health O. The World health report: 2000: Health systems: improving performance. Geneva: World Health Organization; 2000.

8. Straub RH, Cutolo M. Psychoneuroimmunology-developments in stress research. Wien Med Wochenschr. 2018 Mar [cited 2021 Jun 8]; 168(3-4):76-84. Available from: https://doi.org/10.1007/s10354-017-0574-2

9. Schubert C, Hagen C. Bidirectional Cause-Effect Relationship Between Urinary Interleukin-6 and Mood, Irritation, and Mental Activity in a Breast Cancer Survivor. Front Neurosci. 2018 Nov [cited 2021 Jun 8]; $12: 848$. Available from: https://doi.org/10.3389/fnins.2018.00848 